\title{
20 THE SIZE EFFECT IN CONCRETE STRUCTURES
}

\author{
J. OŽBOLT, R. ELIGEHAUSEN and M. PETRANGELI \\ Institut für Werkstoffe im Bauwesen, Stuttgart University, Germany
}

\begin{abstract}
In the present paper the results of a size effect study on plain concrete unnotched and notched beams loaded in three-point bending are shown and compared with experimental results and Bažant's size effect law. The numerical results, obtained using the nonlocal microplane finite element code, confirm a strong size effect for smaller beam sizes. However, for larger unnotched beams the nominal strength tends to a constant value related to the uniaxial tensile strength. These results are in good agreement with what has been observed in experiments. The reason why the nominal strength of large unnotched beams should approach a limit value different from zero is investigated and the range of applicability of the size effect law is discussed. It has been concluded that the applicability of the size effect law is dependent on the problem type i.e. if the crack propagation before peak load is very stable the size effect law may be used in a rather broad size range. However, if this is not the case, the validity of the size effect law is limited to a smaller size range. Therefore, before extrapolating the size effect from tests with a small size range to a very large size range experimental data from a large size range should be available.
\end{abstract}

Keywords: Three-point bending, Concrete, Fracture, Size effect, Size effect law, Nonlocal analysis.

\section{Introduction}

The size effect in quasibrittle materials such as concrete is a well known phenomenon and there are a number of experimental and theoretical studies (Rüsch et al., 1962; Leonhardt and Walter, 1962; Kani, 1967; Bhal, 1968; Taylor, 1972; Walsh, 1976; Walraven and Lehwalter, 1990; Chana, 1981; Reinhardt, 1981 a,b; Iguro et al., 1985; Hillerborg, 1989; Eligehausen et al. 1992) which confirm the existence of it.

There are two aspects of the size effect: (1) Statistical and (2) Deterministic, based on fracture mechanics. In the past, the size effect has been mainly treated from the statistical point of view (Weibull, 1939; Mihashi and Zaitsev, 1981; Mihashi, 1983). However, presently there is much evidence that the main reason for the size effect lies in the release of strain energy due to fracture growth. (Bažant and Cedolin, 
1991).

According to Bažant (1984) the size effect can be approximately described by the size effect law:

$$
\sigma_{N}=B f_{t}(1+\beta)^{-1 / 2} ; \quad \beta=d / d_{0}
$$

in which $d$ is a measure of the structure size (for example beam depth), $f_{t}=$ tensile strength of concrete, $B$ and $d_{0}$ are two constants, to be determined either experimentally or by a more sophisticated analysis. According to Eq. (1) the nominal strength $\sigma_{N}$ of large structures tends to zero and the failure load increases with $\sqrt{d}$.

Under the assumption that the material properties are constant (the same concrete), the derivation of the size effect law is based on four basic hypotheses: (1) The propagation of a fracture or crack band requires approximately a constant energy supply per unit length and width (concrete fracture energy $G_{F}$, independent of the specimen size) (2) the energy released from the structure due to fracture growth is a function of both (a) the fracture length and (b) the area of the cracking zone (fracture process zone) at the fracture front. If the potential energy release is a function of only the fracture length, the size effect is that of linear elastic fracture mechanics, and if it is a function of only the cracking area, there is no size effect. (3) At peak load, the fracture shapes and lengths in geometrically similar structures of different sizes are also geometrically similar, and (4) the structure does not fail at crack initiation i.e. fracture propagation must be possible.

It has been shown that the size effect law is valid for a large number of practical applications (Bažant, Ožbolt and Eligehausen, 1993). However, there are some examples which show that the size effect law is not valid for larger specimens. For instance, in a number of experiments with unnotched beams (Malkov and Karavaev, 1968; Heilmann, 1969) and notched beams with a constant notch depth (Alexander, 1987), it has been observed that the normalized bending strength approaches a limit value different from zero. This behaviour has also be confirmed by linear elastic fracture mechanics (LEFM) under the assumption that the initial notch length remains constant or zero for all member depths (Elices and Planas, 1992) and by Tang, Shah and Ouyang (1992) using two parameter fracture model (TPFM).

To investigate the size effect in more detail, in the present study the behaviour of notched and unnotched plain concrete beams loaded in three-point bending are studied using the nonlocal microplane finite element code.

\section{Size effect in three-point bending of plain concrete beams - review of the evidence}

In literature a number of test results for notched and unnotched three-point bending specimens have been reported. In Fig. 1 test results for three similarly scaled notched beam specimens (notch size - beam depth ratio, $a_{0} / d=1 / 6$ ), performed at Northwestern University (Bažant and Pfeiffer, 1987), are shown. In the same figure these results are compared with numerical results (Eligehausen and Ožbolt, 1992) and the size effect law. The depth of the beam specimens has been varied in a rather small size range i.e. from $d=76 \mathrm{~mm}$ to $305 \mathrm{~mm}$ with a constant thickness $b=38$ 
$\mathrm{mm}$. The nominal strength at failure is calculated using the elastic beam theory formula $\sigma_{N}=15 P_{U} / 4 b d$ with $P_{U}$ being the ultimate load. From Fig. 1, a significant size effect is observed i.e. the nominal strength $\sigma_{N}$ decreases with increasing size. The size effect law shows a good agreement with the experimental results.

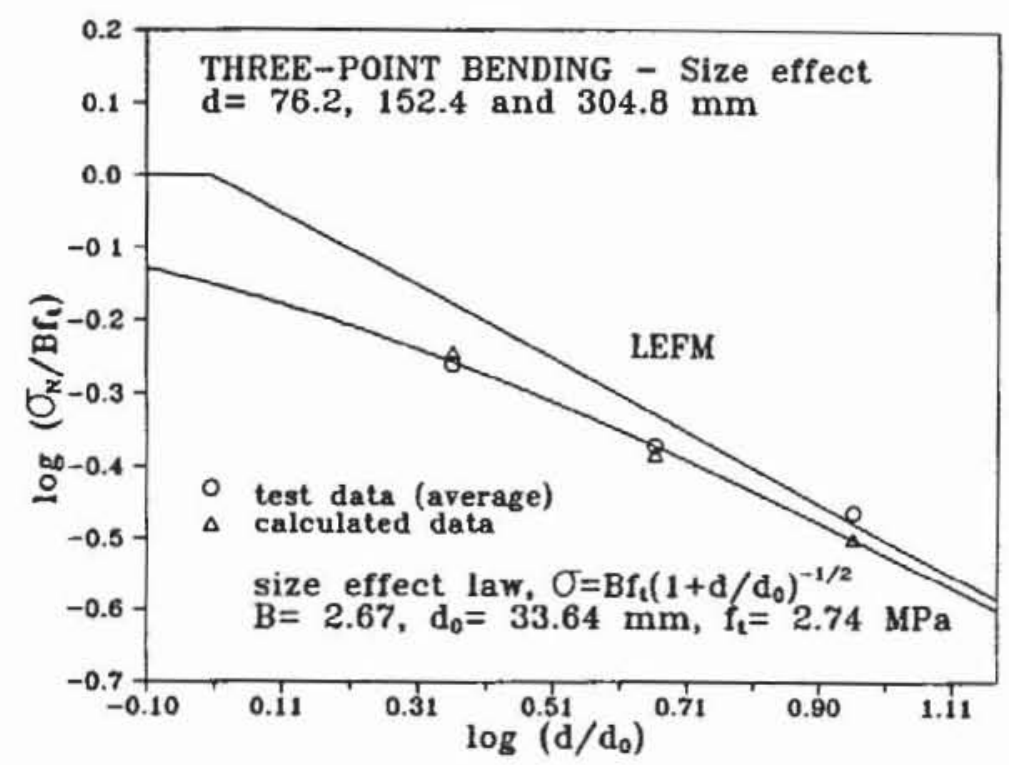

Fig. 1 Size effect in three-point bending notched specimens $\left(a_{0} / d=1 / 6\right)$

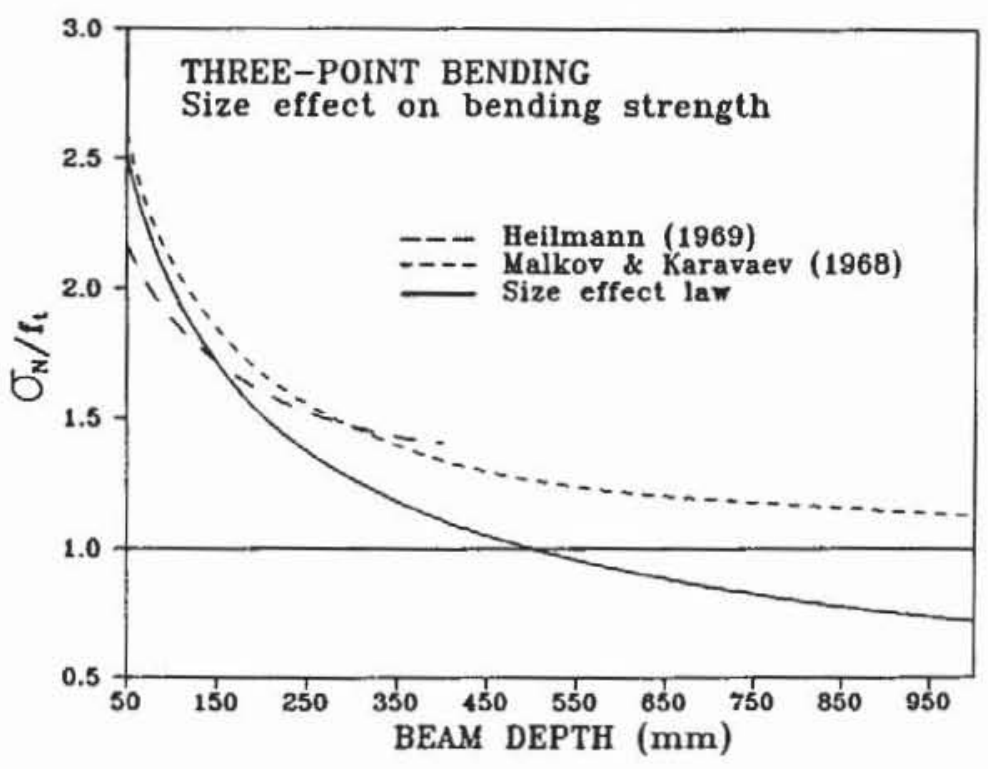

Fig. 2 Size effect in three-point bending unnotched specimens

The test results reported by Malkov and Karavaev (1968) and Heilmann (1969) for unnotched plain concrete three-point bending specimens are plotted in Fig. 2. The beam depth range was up to $1000 \mathrm{~mm}$. As can be seen from Fig. 2, test results up to a beam depth of approximately $d=500 \mathrm{~mm}$ exhibit a significant size effect in relatively good agreement with the size effect law. However, for larger specimens, the nominal strength tends to the uniaxial tensile strength of concrete.

In Fig. 3 the nominal strength of notched beams with a constant notch size, tested by Alexander (1987) are plotted as a function of the member depth. As in 
the case of unnotched specimens, the nominal strength of large beams tends to a constant value different from zero.

Since the experimental results plotted in Figs. 2 and 3 clearly indicate a disagreement with the size effect law for larger beams it is obvious that the size effect law assumptions are not fulfilled.

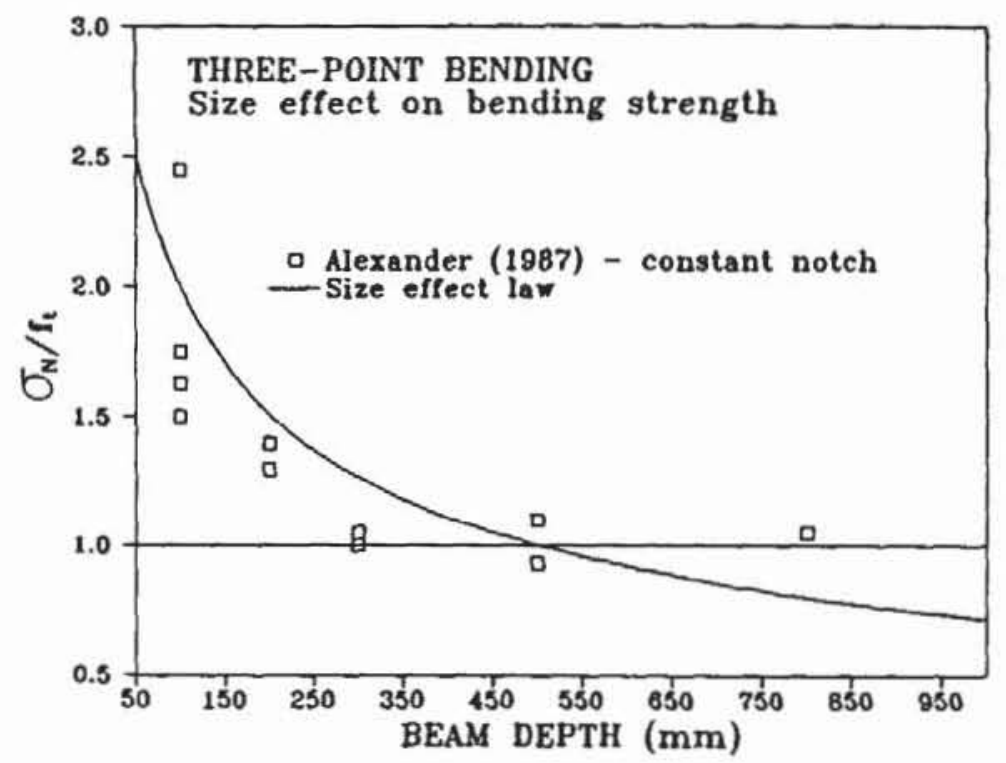

Fig. 3 Size effect in three-point bending notched specimens (constant notch size)

\section{Numerical study}

\subsection{Beam geometries and material properties}

Beam specimens of four different sizes with a constant span-depth ratio $L / d=5$ are analyzed. The depths of the beams are $d=100,200,800,1600$ and $3200 \mathrm{~mm}$ with a constant width of $b=38 \mathrm{~mm}$ (see Fig. 4). Unnotched specimens (Fig. 4a) and notched specimens with a notch depth of $a=d / 6$ and a notch width of $w=$ $30 \mathrm{~mm}$ are analyzed. The material properties are taken as follows: tensile strength $f_{t}=4.5 \mathrm{MPa}$, uniaxial compressive strength $f_{c}=40 \mathrm{MPa}$, Initial Young modulus $E=32000 \mathrm{MPa}$, Poisson's ratio $\nu=0.18$, fracture energy $G_{F}=0.12 \mathrm{~N} / \mathrm{mm}$ and maximum aggregate size $d_{a}=16 \mathrm{~mm}$. The uniaxial tensile strength and fracture energy have been calibrated on a notched tensile specimen with a length-depth ratio $L / d=175 / 75 \mathrm{~mm}$ using the nonlocal finite element code (microcrack interaction approach). The characteristic length was kept constant in all case studies as $l=d_{a}$ $=16 \mathrm{~mm}$.

The finite element nonlinear nonlocal fracture analysis is performed using the microplane model and the nonlocal microcrack interaction approach (Ożbolt and Bažant, 1992; Ożbolt, 1992; Ożbolt and Petrangeli, 1993). The load is introduced by controlling the vertical displacement at mid span of the beam (see Fig. 4). Only one half of the beam is modelled and the size of the elements in the fracture process zone are approximately the same for all beam sizes (element size $\approx 12 \mathrm{~mm}$ ).

For unnotched beams two sets of runs are carried out. In the first, in order to limit the size of the fracture process zone at mid span, a nonlinear zone width of $t=$ 
$200 \mathrm{~mm}$ for all beam sizes is introduced. Outside this zone the material behavior is assumed to be linear elastic (see Fig. 5a). In the second case the nonlinear zone is proportionally scaled with the size of the beams and is taken as $t=L / 5$ (see Fig. 5b) in order to allow for the spreading of damage along the beam length. For notched beams, only finite element meshes with a large nonlinear zone width are used $(t=L / 5)$.

a)

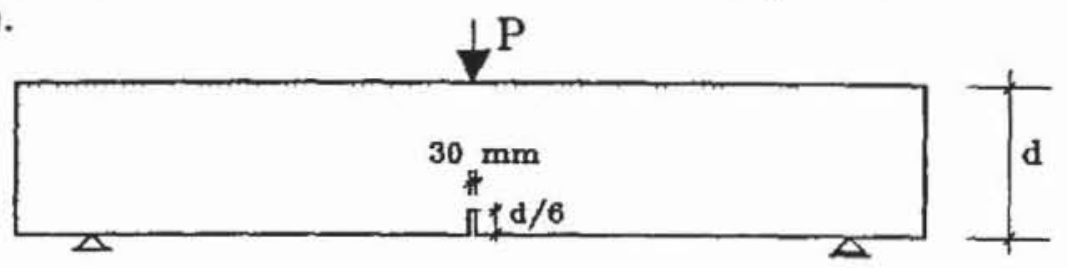

b)

$\stackrel{\mathrm{d} / 2 \mid}{1+} \quad \mathrm{L}=5 \mathrm{~d} / \mathrm{d}$

)

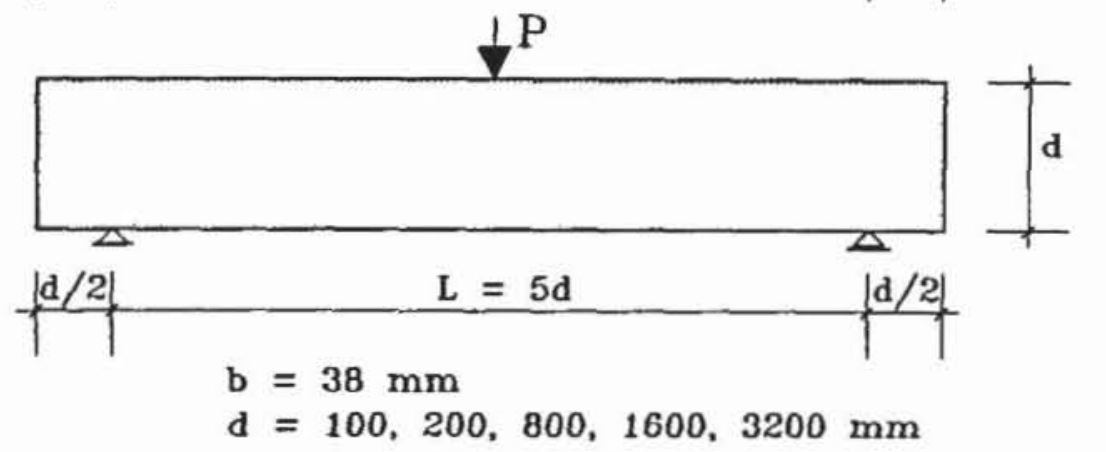

Fig. 4 Geometry of the beams used in the numerical analysis
a) notched
b) unnotched

a)

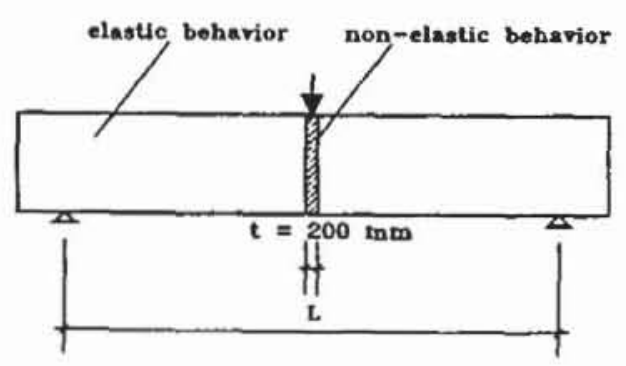

b)

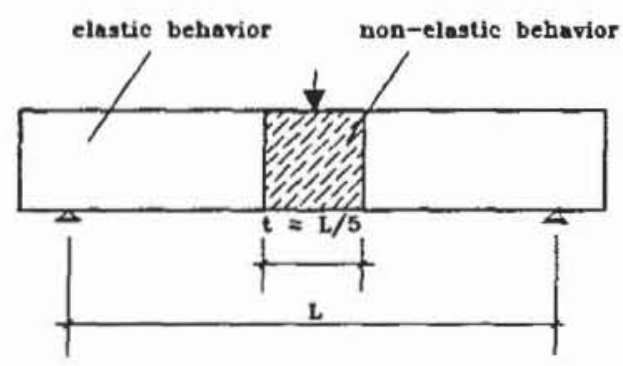

Fig. 5 (a) Small nonlinear zone (b) Large nonlinear zone

\subsection{Results of the analysis - notched beams}

In Fig. 6 the calculated nominal strength for notched beams are plotted and compared with the available test data (Bażant and Pfeiffer, 1987). The nominal strength is calculated for the net cross-section area according to elastic beam theory. In the same figure the nominal strength predicted by the size effect law is also plotted. As expected, the calculated results confirm the size effect law prediction since the initial specimen geometry (i.e. constant notch-depth ratio $a / d$ ) fulfills the main assumption of the size effect law. 
3.3 Results of the analysis - unnotched beams

In Fig. 7 the nominal strengths for both unnotched beam sets are plotted. The nominal strength is defined as the maximum stress of an elastic beam subjected to the ultimate load $P_{U}$ found with the nonlinear analysis. Experimental results and the size effect law (from Fig. 1) are plotted for comparison. The experimental results have been extrapolated up to a beam depth of about $3 \mathrm{~m}$ using the equation proposed by Malkov and Karavaev (1968).

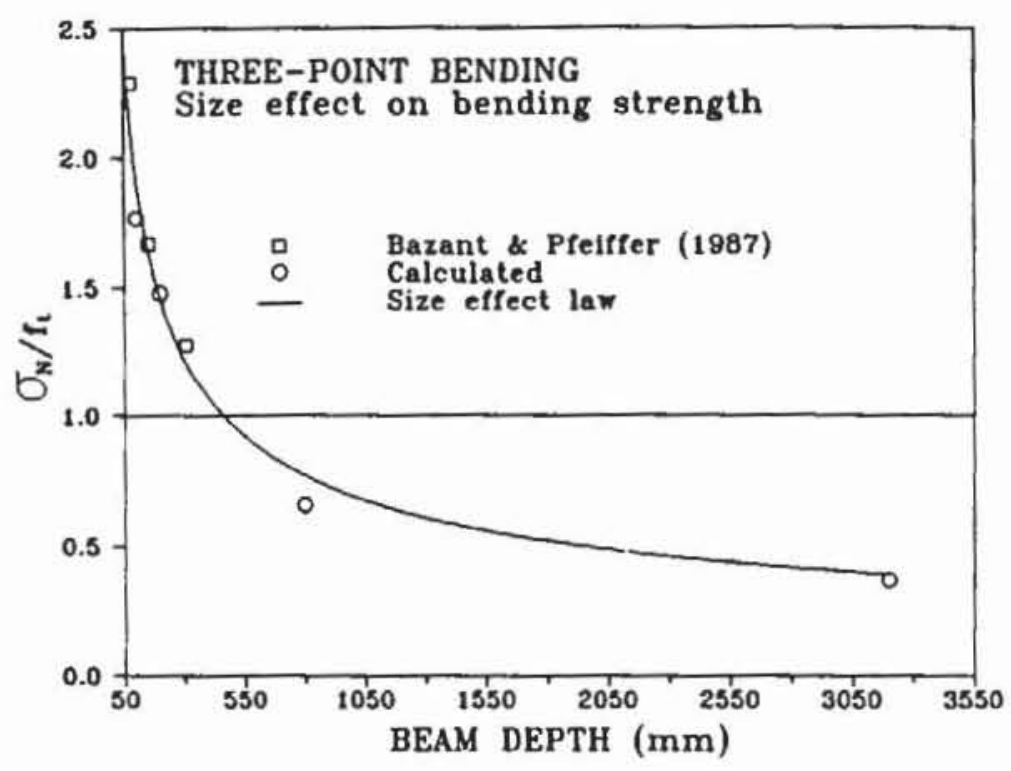

Fig. 6 Nominal strength for notched beams

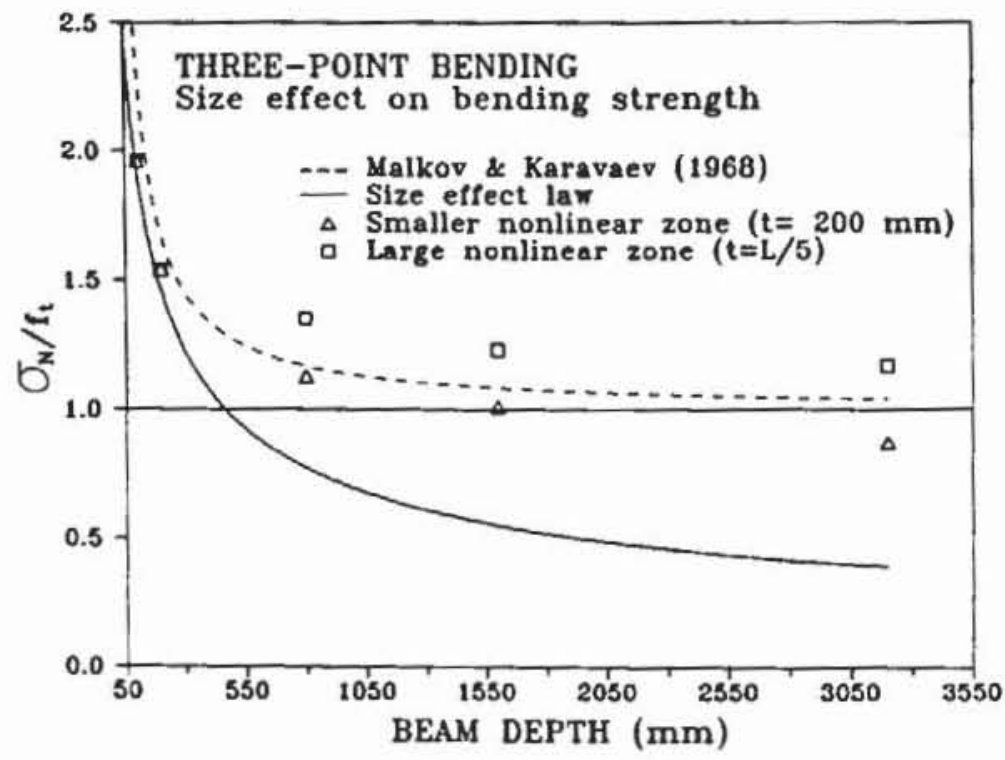

Fig. 7 Nominal strength for unnotched beams

The nominal strength of the beams with a larger nonlinear zone in the critical mid span section approaches the uniaxial tensile strength. When assuming a smaller width of the nonlinear zone the nominal strength decreases faster with increasing beam size than in the case of a large nonlinear zone. The calculated nominal 
strengths for the smaller nonlinear zone lie between the size effect law prediction and the calculated results of the beams with the larger nonlinear zone. The numerical results for the beams with a larger nonlinear zone agree sufficiently well with the experimental observations, but disagree with the size effect law for beam depths in excess of about $d \cong 500 \mathrm{~mm}$.

a)

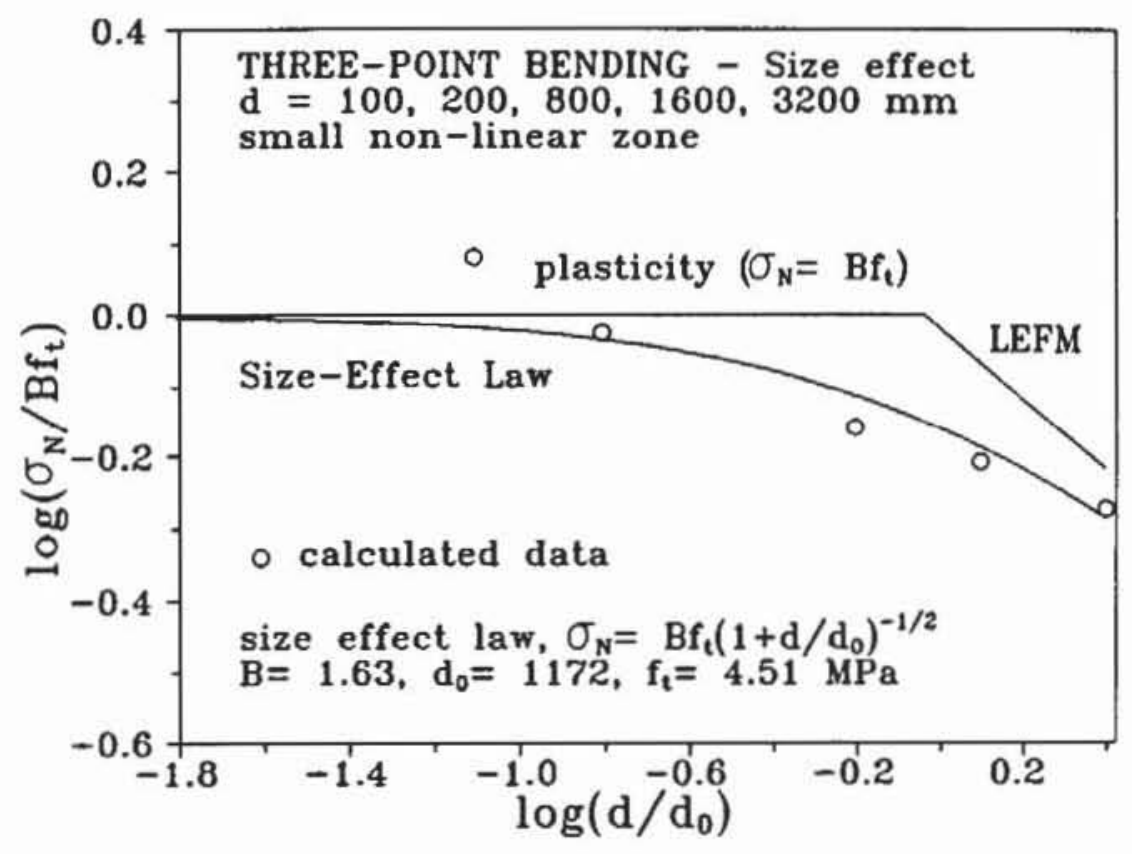

b)

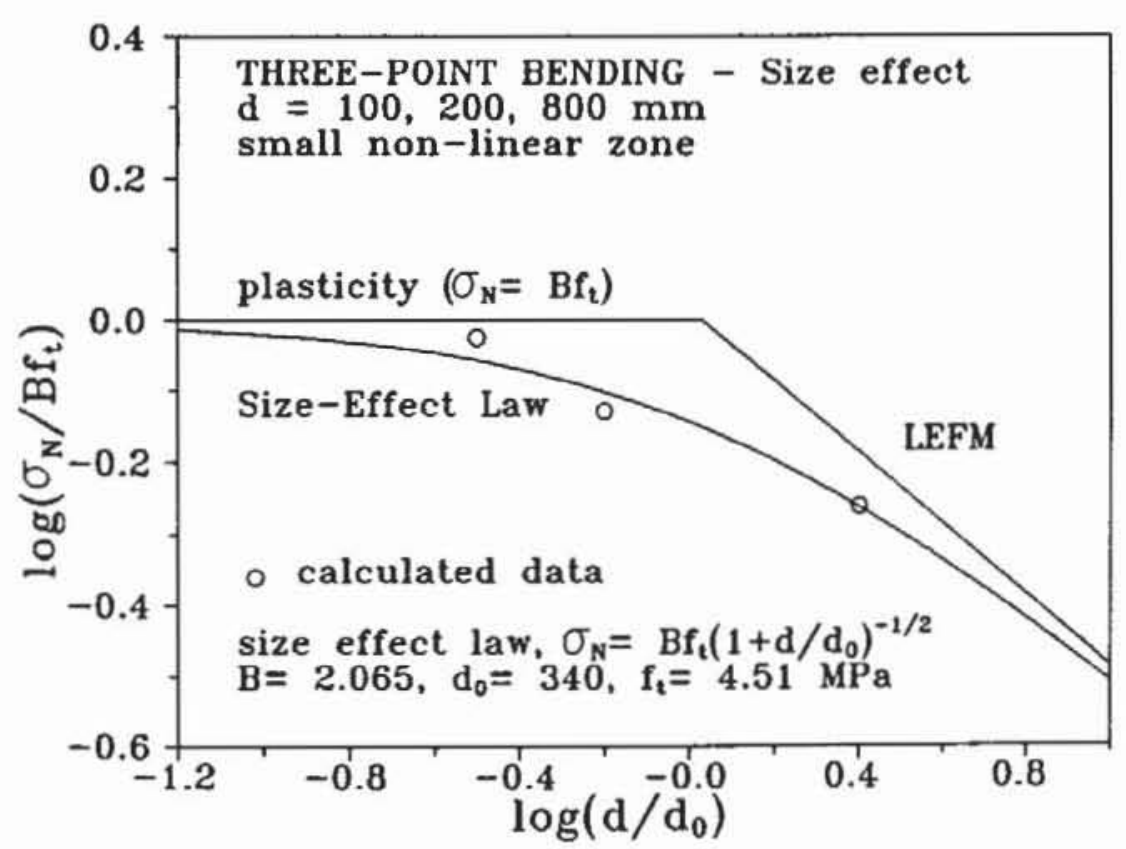

Fig. 8 Fit of the numerical results with the size effect law for smaller nonlinear zone (a) large size range (b) small size range 
In Figs. $8 \mathrm{a}$ and $9 \mathrm{a}$ the results of both sets of the analysis (limited and large nonlinear zone) are compared with the size effect law in a size range from $d=100$ to $3200 \mathrm{~mm}$. As can be seen, it is not possible to obtain a good fit of the calculated data with the size effect law. However, when fitting the numerical results for smaller beam depths $(d=100,200$ and $800 \mathrm{~mm})$ with the size effect law the agreement is much better (see Figs. $8 \mathrm{~b}$ and $9 \mathrm{~b}$ ). This shows that there is a significant size effect for smaller beam sizes only.

a)

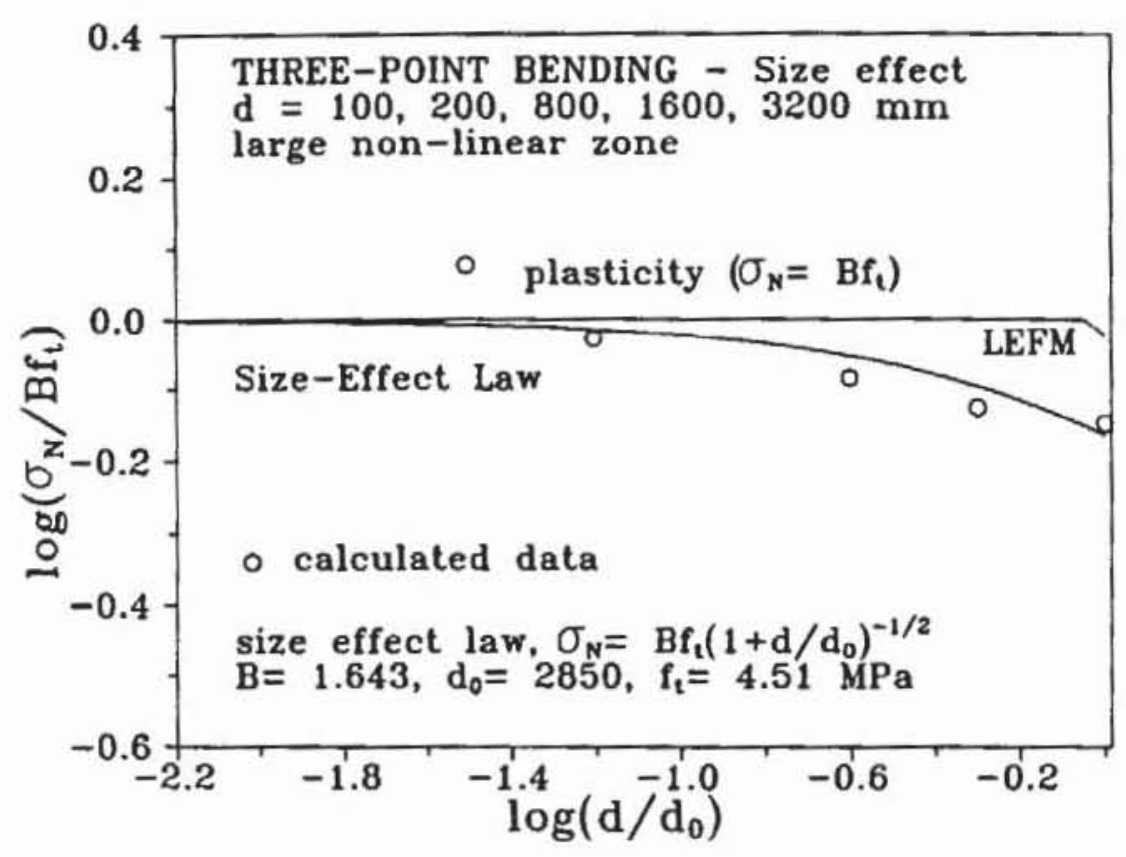

b)

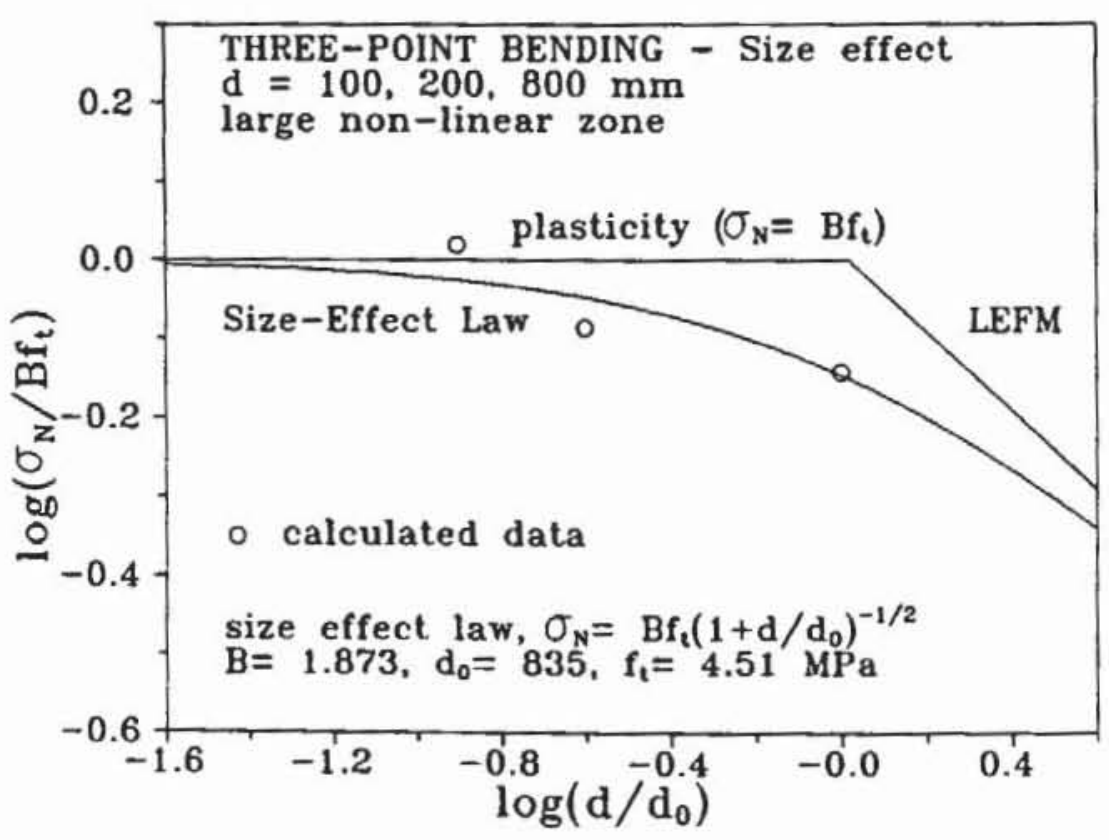

Fig. 9 Fit of the numerical results with the size effect law for larger nonlinear zone (a) large size range (b) small size range 


\section{Explanation and discussion}

To understand the reason for the disagreement between tests as well as numerical results and the size effect law prediction for unnotched beams, let us first consider the variation of strains in the bottom layer of the beam. Under the assumption of the elastic bending theory, the variation of these strains at midspan with respect to beam length is:

$$
\frac{d \epsilon}{d x}=\frac{3 P}{b d^{2} E}
$$

where $P$ is the force at mid span and $E$ Young modulus. If $d \rightarrow 0$ than from Eq. (2) it follows $\frac{d \epsilon}{d x} \rightarrow \infty$. However, if $d \rightarrow \infty$ than $\frac{d \epsilon}{d x} \rightarrow 0$. This means that for smaller beam sizes the strain gradient along the bottom beam edge is very large, and on the contrary, for extremely large beams it is close to zero. Therefore, in smaller beams, due to the relatively large localization of strains, a fracture zone at mid span of the beam forms when reaching the uniaxial tensile strength. The crack i.e. the softening zone, can then propagate in a stable manner since for a smaller beam the fracture energy release per unit crack growth is less than the critical energy release for the concrete $\left(\frac{d G}{d a}<G_{F}\right)$. Failure occurs when the crack propagation becomes unstable i.e. $\frac{d G}{d a} \geq G_{F}$. Therefore, the nominal stress at failure is controlled by the material fracture energy and the size effect law is approximately valid.

In contrast to smaller beams, in very large beams the strain gradient along the bottom beam length at midspan is very small. This causes two different phenomena: (1) The size of the damaged material volume is not constant but varies with the structural size which means that there is an energy consumption prior to the macrocrack localization in the material volume which is to a certain extent proportional to the structural size, (2) when the damage localizes into the final macrocrack, due to the large stored energy the beam fails without crack propagation since $\frac{d G}{d a}>G_{F}$. Because of these two phenomena, there is no crack growth proportionality at peak load. Therefore, for large beams the nominal strength is controlled by the uniaxial tensile strength and failure occurs in a very brittle manner without any possibility for crack growth i.e. failure at crack initiation. As a consequence, the size effect law does not apply. This is the case for both sets of beams (large and small nonlinear zone), except that for a smaller nonlinear zone the damaged volume of the material is relatively small and therefore the energy consumption before reaching peak load is smaller. As a consequence, the size effect is stronger for a larger size range.

To confirm the above discussion in Fig. 10 the vertical lengths of the softening zone for unnotched beams at peak load, relative to the beam depth, are plotted as a function of the beam depth. It can be seen that the depth of the softening zone at peak load for smaller beams is relatively large i.e. for a beam size $d=100 \mathrm{~mm}$ the softening zone approaches approximately $1 / 2$ of the beam depth. In contrast to this, in a large beam $(d=3200 \mathrm{~mm})$ the depth of the softening zone is small. Clearly, the lengths of the softening zone at peak load, or in terms of LEFM the effective crack lengths, are not proportional to the beam size.

The effect of nonlocality of damage on the size effect can be seen by comparing 
the results for unnotched beams with a small and large nonlinear (nonlocal) zone see Fig. 7. It follows that the nominal strength tends to a constant value which is dependent on the size of the nonlinear (nonlocal) zone. When this zone is getting smaller the size effect is stronger in a larger size range. This is due to the fact that by limiting the nonlinear zone the damage is distributed in a smaller material volume. As a consequence, the size effect is stronger in a larger size range.

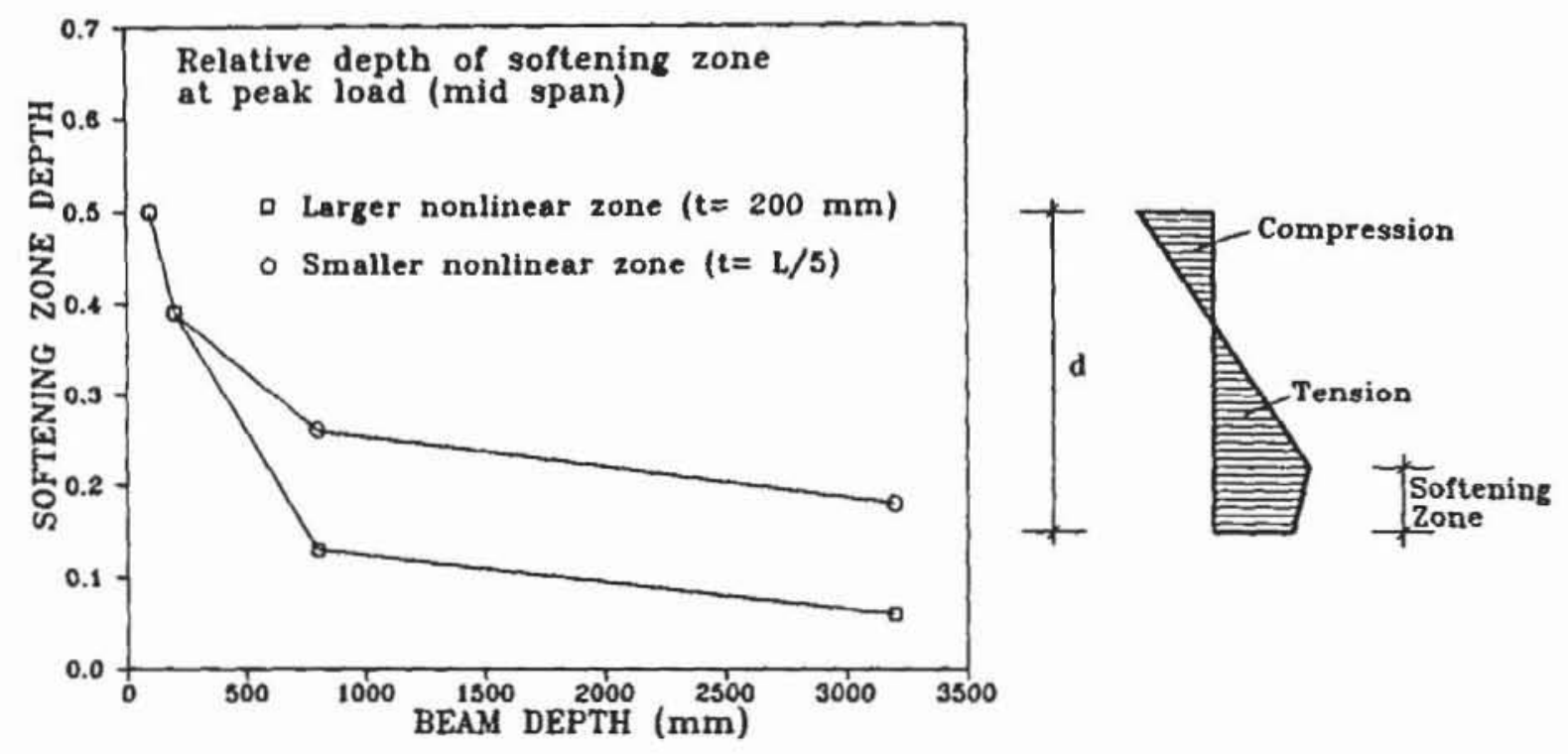

Fig. 10 Relative length of the softening zone at peak load as a function of bearn depth

The fracture analysis results for unnotched beams of different sizes can be summarized as shown in Fig. 11. It shows that the failure load for very small beams is governed mainly by plasticity and for very large beams by a strength criteria. In medium size ranges instead, the failure load is influenced by the fracture process what can be interpreted as a fracture stiffening effect on the failure load. In this size range, when approaching the structure failure load, the material strength will be reached first and then a crack will start to propagate, if it is possible, until reaching unstable crack propagation.

Related to the above discussion the question arises, what is the transition between both limit cases i.e. large size effect and almost no size effect. It seems that this is mainly controlled by the problem type (geometry of the specimen and loading conditions). For normal plain concrete unnotched beams, according to the results of the present numerical investigation, this transition is taking place between a beam depth of $d=500$ and $1000 \mathrm{~mm}$.

More generally, when using the same arguments as above, it follows that in the case when the strain gradient $\left(\frac{d e}{d x}\right)$ in the fracture process zone approaches zero rather slowly for $d \rightarrow \infty$ (strong localization), the size effect will be strong in a rather broad size range since stable crack propagation will be possible. If this is not the case, the size effect on the nominal strength will be strong only for a very 
limited size range after which a strength limit will be reached. Therefore, the size range over which the size effect law is valid should depend on the problem type.

To check the validity of the above discussion, tests on rather large specimens are needed. However, the tests performed in the past covered a relatively small size range only. For beams without shear reinforcement, failing in diagonal shear, most test results are limited to a beam depth of one meter (Walraven and Lehwalter, 1990). For headed studs, failing by pulling out a concrete cone, the maximum embedment depth is about $500 \mathrm{~mm}$ (Eligehausen and Sawade, 1989). In these size ranges the size effect law applies. However, the question is whether this holds true also for larger sizes.

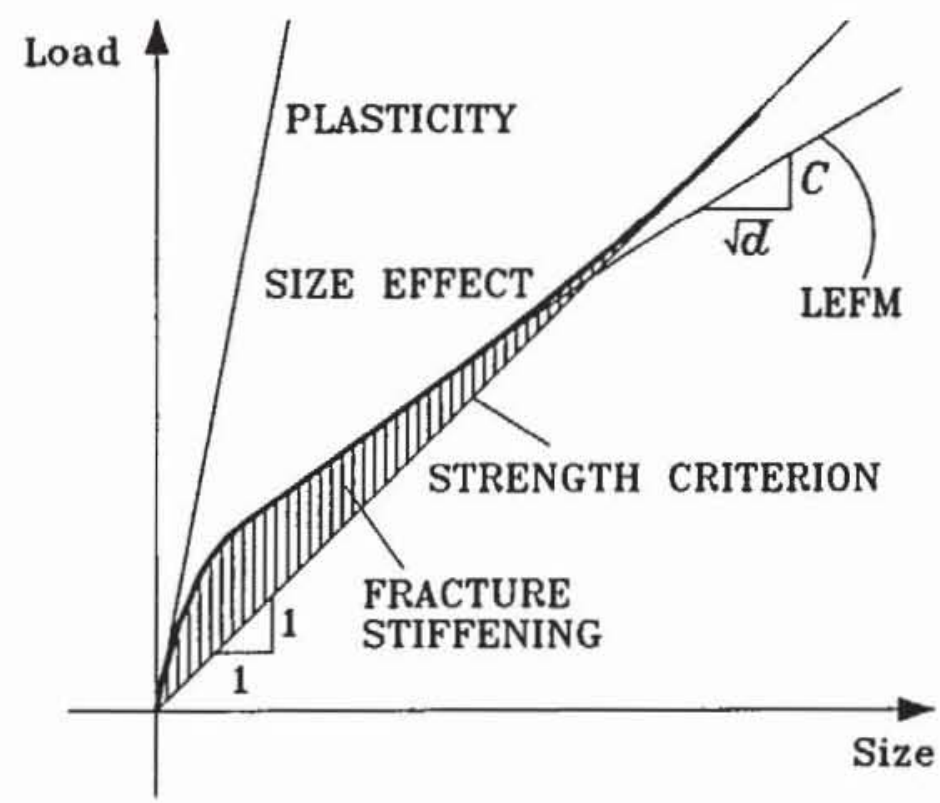

Fig. 11 Fracture stiffening effect

\section{Conclusions}

(1) The nonlocal microplane finite element code is well suited for the fracture analysis of unnotched and notched unreinforced concrete beams failing in threepoint bending.

(2) The calculated nominal strength of notched beam with $a / d=$ constant follows Bažant's size effect law, because the principal assumptions for deducing Eq. 1 are fulfilled.

(3) The calculated nominal strength of unnotched beams indicate a significant decrease of the nominal strength for smaller beam depths (up to approximately $500 \mathrm{~mm}$ ). However, for larger beams the nominal strength approaches a constant value approximately equal to the concrete uniaxial tensile strength. This 
is in agreement with experimental results.

(4) Good agreement between Bażant's size effect law, numerical results and experiments is observed only for smaller unnotched beam sizes (up to $d \approx 500$ $\mathrm{mm})$. For larger beam depths the size effect law disagrees with the experimental evidence and the numerical results. This is due to the fact that the strain gradient for larger beams decrease significantly with increasing size and therefore the damage localization is prevented.

(5) If one applies the same arguments more generally, then for any problem type the nominal strength should tend to a constant value which is different from zero and limited by the material strength. As a consequence, transition between strong size effect and no size effect must exists. The size at which this transition is taking place depends on the problem type.

(6) To check the validity of the above statement, experimental results are needed for larger structures since an extrapolation from small size range test results, where the size effect is always present, to a very large structure sizes is generally not possible.

\section{Acknowledgments}

The authors thanks Mr. R. Okelo for helping in preparing the paper and Institute für Werkstoffe im Bauwesen for the financial support.

\section{References}

Alexander (1987), see Tang, T., Shah, S., and Ouyang, C. (1992). Fracture Mechanics and Size Effect of Concrete in Tension. Journal of Structural Engineering, ASCE, 118(11), 3169-3185.

Bažant, Z.P. (1984) Size effect in Blunt Fracture: Concrete, Rock, Metal. Journal of Engineering Mechanics, ASCE, 110(4), 518-535.

Bażant, Z.P. and Pfeiffer, A.,(1987) Determination of Fracture Energy from Size Effect and Brittleness Number. ACI Materials Journal, 84-M41, 463-480.

Bažant, Z.P. and Cedolin, L. (1991) Stability of Structures: Elastic, Inelastic, Fracture and Damage Theories, Oxford University Press, New York.

Bažant, Z.P., Ožbolt, J. and Eligehausen, R., (1993) Fracture Size Effect: Review of Evidence for Concrete Structures. Submitted to Journal of Str. Eng., ASCE.

Bhal, N.S. (1968) Über den Einfluss der Balkenhohe auf die Schubtragfähtigkeit von einfeldrigen Stahlbetonbalken mit und ohne Schubbewehrung. Doctoral thesis, Unversität Stuttgart, $124 \mathrm{pp}$. 
Chana, P.S. (1981) Some Aspects of Modeling the Behavior of Reinforced Concrete under Shear Loading. Technical Report Nr. 543, Cement and Concrete Assoc., Wexham Springs, $22 \mathrm{pp}$.

Elices, M., and Planas, J., (1992) Size Effect in Concrete Structures: $R$-Curve Approach. Application of Fracture Mechanics to Reinforced Concrete, Ed.by A. Carpinteri, Elsevier Applied Science, Torino, Italy, 169-200.

Eligehausen, R. and Sawade, G. (1989) A fracture mechanics based description of the pull-out behavior of head studs embedded in concrete, Fracture Mechanics of Concrete Structures - RILEM Report, (ed L. Elfgren), Chapman and Hall, pp. 263-280.

Eligehausen, R., and Ožbolt, J. (1992) Size Effect in Concrete Structures. Application of Fracture Mechanics to Reinforced Concrete, Ed.by A. Carpinteri, Elsevier Applied Science, Torino, Italy, 17-44.

Eligehausen, R., Bouška, P., Cervenka, V. and Pukl, R. (1992) Size Effect of the Concrete Cone Failure Load of Anchor Bolts. FramCoS 1, Ed. by Bažant, Z.P., Elsevier applied science, Breckenridge, USA, 517-525.

Heilmann, H. G., (1969) Beziehungen zwischen Zug- und Druckfestigkeit des Betons. Beton, 2, 68-72.

Hillerborg, A. (1989) Fracture Mechanics and the Concrete Codes. Fracture Mechanics: Applications to Concrete, ACI-SP118, Ed. V. Li and Z.P.Bažant, 157-170.

Iguro, M., Shioya, T., Nojiri, Y., and Akiyama, H. (1985) Experimental Studies on Shear Strength of Large Reinforced Concrete Beams under Uniformly Distributed Load. Concrete Library International, Japan Society of Civil Engineers, No. $5,137-154$.

Kani, G.N.J. (1967) How Safe are Our Large Reinforced Concrete Beams? Journal of American Concrete Institute, 64(3), March, 128-141.

Leonhardt, F. and Walter, R. (1962) Beiträge zur Behandlung der Schubprobleme im Stahlbetonbau. Beton- und Stahlbetonbau (Berlin), March, 56-64, and June, 141-149.

Malkov, K. and Karavaev, A., (1968) Abhängigkait der Festigkeit des betons auf Zug bei Bigung und ausmittiger Belastung von den Querschnittsabmessungen. Wischenshaftliche Zeitschrit der Technischen Iniversität Dresden, 17(6), 1545-1547.

Mihashi, H., and Zaitsev, J.W. (1981) Statistical Nature of Crack Propagation. Section 4-2 in Report to RILEM TC 50 - FMC, Ed., F.W. Wittmann.

Mihashi, H. (1983) A Stohastic Theory for Fracture of Concrete. in Fracture Mechanics of Concrete, Ch. 4.3, Ed. by F.H. Wittmann, Elsevier, Amsterdam, NY, 301-340.

Ožbolt, J. and Bažant, Z. P. (1992) Microplane Model for Cyclic Triaxial Behavior of Concrete. Journal of Eng. Mech., ASCE, 118, (7), 1365-1386.

Ożbolt, J. (1992) Smeared Crack Analysis - New Nonlocal Microcrack Interactions Approach. Internal Report No. 4/14-92/19, Institut für Werkstoffe im Bauwesen, Stuttgart University, Germany.

Ožbolt, J. and Petrangeli, M. (1993) Improved Microplane Model for Concrete. 
Internal Report No. 4/17-93/5, Institut für Werkstoffe im Bauwesen, Stuttgart University, Germany.

Reinhardt, H.W. (1981 a) Similitude of Brittle Fracture of Structural Concrete. IABSE Colloquium on Advances in Reinforced Concrete, Delft, 175184.

Reinhardt, H.W. (1981 b) Masstabseinflusse in Schubversuchen im zicht der Bruchmechanik. (in German), Beton u. Stahlbetonbau, Berlin, 76(1), 19-21.

Rüsch, H., Haugli, F. R., and Mayer, H. (1962). Schubversuche an StahlbetonRechteckbalken mit gleichmässig verteilter Belastung. Bulletin No. 145, Deutscher Ausschuss für Stahlbeton, Berlin, 4-30.

Tang, T., Shah, S., and Ouyang, C. (1992). Fracture Mechanics and Size Effect of Concrete in Tension. Journal of Structural Engineering, ASCE, 118(11), 3169-3185.

Taylor, F.P.J. (1972) The Shear Strength of Large Beams. Journal of Structural Engineering, ASCE, 98, 2473-2490.

Walraven, J. and Lehwalter, N. (1990) Einfluss des Massstabs in schubbeanspruchten Bauteilen ohne Schubbewehrung. Beton- und Stahlbetonbau, 85, H. 9, 228 232.

Walsh, P.F. (1976) Crack Initiation in Plain Concrete. Mag. of Concrete Research, Vol. 28, 37-41.

Weibull, W., (1939) Phenomenon on Rapture in Solids. Ingenioersvetenskapsakad Handl, V. 153, 1-55. 